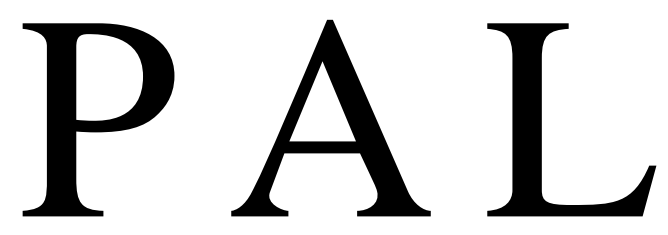

REVIEW

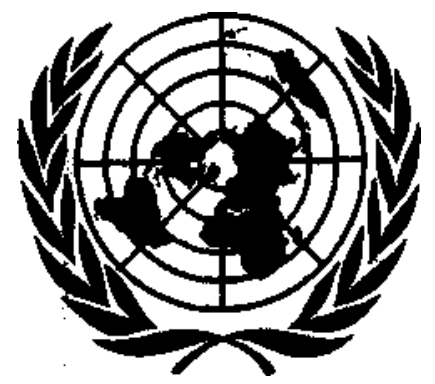

UNITED NATIONS 


\section{CEPAL Review}

Executive Secretary

Norberto González

Deputy Executive Secretary for Economic and Social Development Gert Rosenthal

Deputy Executive Secretary for Co-operation and Support Services Robert T. Brown

Director of the Review

Raúl Prebisch

Technical Secretary

Adolfo Gurrieri

Deputy Secretary

Rosa Nielsen

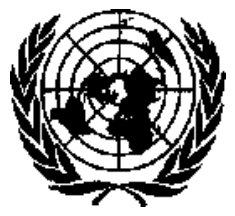

UNITED NATIONS

ECONOMIC COMMISSION FOR LATIN AMERICA AND THE CARIBBEAN

SANTIAGO, CHILE, APRIL 1986 


\section{E P A L}

Review

Santiago, Chile

Number 28

\section{CONTENTS}

Address delivered by the Executive Secretary of ECLAC, Mr. Norberto González, when opening the Meeting on Growth, Adjustment and the Debt in Latin America.

Central America: Bases for a reactivation and development policy. ECLAC Mexico Subregional Headquarters

Thoughts on industrialization, linkage and growth. Joint ECLAC/UNIDO Industrial Development Division

Inflation and stabilization policies. Daniel Heymann

Transnational corporations in Argentina, 1976-1983. Daniel Aspiazu, Eduardo Basualdo and Bernardo Kosacoff

Social security and development in Latin America. Carmelo Mesa-Lago

Changes of social relevance in the transplantation of theories: the examples of economics and agronomics. Ivo Dubiel

The preparation of natural and cultural heritage inventories and accounts. Nicolo Gligo

Co-operativism and popular participation: new considerations regarding an old subject. Roberto P. Guimarães

Notes on trade from the standpoint of the periphery. Raúl Prebisch 


\section{Introduction}

Thoughts on industrialization, linkage and growth

\section{Joint ECLAC/UNIDO Industrial Development Division}

This article discusses some issues which ought to be taken into consideration in the preparation of a new industrialization strategy that will make it possible to deal with internal disequilibria and face up to the predictable international situation in the coming years. The first section expounds the concept of linkage, which is regarded as the most significant of the attributes differentiating the productive and social structures of the advanced countries from those of the countries of the Latin American region. In the former, the characteristic feature is organic and interdependent growth of the various parts of the industrial complex, and in the latter, a transplantation of fragments of that structure which leaves in external hands complementary aspects of crucial importance for the functioning of the whole.

In the second part a definition is given of the concept of "nucleus of technological dynamization" which comprises a positive valuation, by those exercising leadership, of the national significance of filling internal gaps and of promoting firmly-based insertion in the world economy; a modus operandi characterized by fluid communication and linkage between the various agents and sectors; and a generalized social attitude of esteem for creative activity and for the entrepreneurial function.

In the third section examples from countries in other regions are adduced to show that there is no such thing as a contradiction between import substitution and exports. All the countries that have been successful in their industrialization have made complementary use of both, but what has been peculiar to Latin America in the import-substitution process has been the lack of creativity.

Other aspects are next explored which would be of help in forming a strategy, such as the dichotomy between State and market, and the supposed leadership of the services and communication sector, and the article concludes with some general observations on the need to revivify industrialization strategy in order to overcome the debt crisis.
In the coming years the countries of Latin America will have to face, inter alia, the challenges posed by the imperative need to gradually resolve the disequilibria in the structure of domestic production, as well as the accumulation of social needs that were shelved during the preceding period of rapid growth and are now beginning to clamour for attention; by the change of sign in the external financing situation, which used to be a source of stimulus and support for growth and which has become, at least over the short and medium term, a factor of inhibition and an obstacle to internal economic growth; and by the industrial and technological restructuration in the advanced countries which in some sectors could radically reduce the possibilities of international competition open to the production of the various Latin American countries. On these three spheres the topic of industrialization has a direct bearing.

Latin America's particular development and industrialization pattern is to a large extent a legacy of the great crisis of the 1930s. There seem to be no grounds for assuming that this pattern could persist during the present crisis without undergoing structural modifications. Rather is it urgently necessary to seek a new industrialization strategy which will make it possible to cope with internal imbalances and take a clear-sighted view of the predictable international situation in the coming years. Something will next be said on the subject of linkage between sectors, agents and markets, which is considered of key importance for reflection upon strategical adjustments in Latin American development. 


\section{Industrialization patterns and concept of linkage}

The concept of linkage (like its opposite, delinking) serves to characterize both the structure of national production systems and its side-effects in the social, spatial and even cultural spheres. This concept is perhaps the most significant of the attributes that differentiate the productive and social structures of the advanced countries from those of the countries of the Latin American region.

From the standpoint of their gestation, linked structures reflect the transformations initially undergone by agricultural production processes, and based, in the first stage, on biological and organizational changes that made it possible to generate surpluses against which the process of industrialization was begun. This industrialization process was characterized by its functionality in relation both to the demands of subsequent agricultural expansion -in a phase when inputs and equipment of industrial origin came to play a role of growing importance in productivity increments - and to the demand for simple consumer goods that can be mass produced, resulting from the population's enjoyment of a sufficiently large share in the increase in income which the dynamics in question generates. The technological path chosen - which was different and specific in every case of linked development and consistent with the relative scarcities of national resources - enabled agricultural and industrial demand to reinforce each other. It started, in the pre-industrial phase, with simple and relatively low-cost innovations, which were susceptible of incorporation by the great majority of producers, and which gradually became more complex as industrial development allowed them to do so, thanks both to the supply of inputs and equipment and to the growth and expansion of diversified demand for consumer goods.

The dynamic effect of this creation of reciprocal demands was not confined to the sphere of relations between agriculture and industry, but was extended to relations between different branches of industry (consumer goodscapital goods), different types and sizes of production units (large firm-medium-sized and small firm) and different regions, giving rise to a process of relative homogenization of levels of productivity in all the above-mentioned spheres, allowance being made for the disparities necessarily created by the technological leadership that certain firms or branches of production exercised.

In by far the majority of cases, the evolution of these linkage processes called for greater flexibility of social structures and radical changes in the State-civil society relationship, such as those generated by the Puritan revolution in England, the French Revolution, enlightened despotism in the Netherlands, the Civil War in the United States and the restoration of the Meiji Empire.

In contrast to these processes of gradual linkage characteristic of the advanced countries, the countries of Latin America are witnessing a dynamic movement wtyich bears the stamp of the basic structural matrix forged during the colonial period; the impact of this was felt, above all, in the critical phase when relations between agriculture and industry were shaped and the domestic markets were formed and developed. The mining enclaves and the hacienda and plantation structures superimposed in many instances on peasant communities of a different origin gave rise to patterns of demand, both for consumer goods and for equipment, which were incapable of encouraging mass production of simple standardizable goods; they inhibited, along with these, the creation of a "virtuous circle" of agro-rurai and urban-industrial demand comparable with that described by the advanced countries. The technologivcal path adopted in modernization processes accentuated the original bimodality of the structures of production and was influential in the passive 
assimilation of options gestated in other contexts and divorced from what the relative shortage of national resources would have made advisable. In this way the multiplier effects of demand were diverted out of the region or conditions were created for a form of industrialization designed to meet the needs engendered by premature adoption of consumption patterns proper to advanced countries with no such possibility as existed there that they might spread to the great majority of the population. The organic and interdependent growth of the different parts of the industrial complex, which had taken place in the advanced countries, under the spur of the market in some (cases of "modernization from below") or under the guidance of the State in others (situations of "modernization from above"), was replaced in the Latin American region by transplantation of fragments of that structure, while complementary aspects which proved of crucial importance for the functioning of the whole were left in outside hands.

\section{The concept of an endogenous nucleus of technological dynamization}

As has been said before, growth is not sufficient in itself to breed creative capacity, and Latin America can produce plenty of concrete examples to bear this out. One of the predominant features of industrialization in Latin America has been, in countries with different characteristics, its rapid growth since the Second World War, and at the same time, as a trait complementary to this growth, it is precisely the lack of creative capacity that may be mentioned, albeit certain spheres of relative excellence have existed in most of the countries (Katz, 1980).

It may well be asked, then, what are the other conditions required to ensure the development of the inventive spirit, since it can be seen that growth is not enough. To start with, there is the fact that creation is a complex process in which a wide variety of agents and motivations take part - large industrial plants linked with small and medium-sized ones, institutes of technology, institutes of basic science, organizations that train skilled personnel at the various levels, the mass communication media and the Ministries and central agencies which define policies and norms-, and for which the interaction of these agents and motivations is decisive. Accordingly, it may be inferred that among the factors which can help to develop or to frustrate this activity an important role should be played by the type of relations established between the various agents of economic activity and between the individuals participating in each of the said activities and the place of work in question. Consequently, creation would also be influenced by the pattern of labour relations within each of these agencies or entities and the nature of the relations established between those various activities. It is highly unlikely that an industrial model which derives its impulse from subsidiaries of firms whose centres of gravity are located in other countries will unleash an internal creative process because such a thing is not functional, generally speaking, for those firms' long-term expansion strategy. Nor has a development model essentially based on the mere export of natural resources any need for creative activity to be developed either by individuals or by producer enterprises. In addition, therefore, to the nature of the agents and the relations established between and within them, another important explanatory factor of creation is the structure of production through which economic activity is given concrete expression. 
Outstanding among the various factors that affect the process of creation is the degree of decentralization of economic life. One of the major conditions would seem to be that the interacting units should have a wide enough margin of autonomy as regards fomenting the creative faculty both to take the offensive or assume the defensive with respect to innovations, and to encourage their inventors.

When communication, interaction and smooth linkage between these decision-making agents, institutions and levels are consolidated as an everyday practice on the national plane, it will signify the formation of what is defined hereinafter as an "endogenous nucleus of technological dynamism". If this concept is to be applicable in practice it must be broken down by its basic dimensions, namely:

a) Positive valuation, by those who exercise leadership, of the national significance of meeting internal needs and of promoting firmlybased insertion in a world economy characterized by increasing transparency and intercommunication;

b) A modus operandi characterized by smooth communication and linkage between the various economic and social agents and sectors which participate in the production of goods and services; and

c) A generalized social attitude of esteem for creative activity and the entrepreneurial function, irrespective of the set-up as regards forms of ownership (which will be conditioned by the specificity of the historical processes that moulded the different societies concerned). This valuation of the creative faculty presupposes a spirit of great openness towards the rest of the world, both in relation to the learning process and the assimilation of knowledge generated outside the region, and with respect to the identification of those activities in which a country can attain levels of relative excellence that will enable it to generate the foreign exchange indispensable for purchasing the goods and services it requires, in conjunction with those locally produced, to meet its own needs. This systematic learning process implies an obsessive concern with the permanent training of the population, through educational media, specialized institutions, and the mass communication media, as well as an exhaustive knowledge of local potentialities comprising both the natural resources available and the possibilities of modernizing the organizational patterns and the traditional techniques at the country's disposal. Genuine modernization is that which enhances the wealth and potential of the patrimony inherited on the various planes: the legacy of the past, values and aptitudes, forms of organization and know-how associated with local specificities. This kind of modernization permits insertion in international markets, because it adds intellectual value and efficiency to the production designs, processes, techniques and organizational patterns which already existed. Modernization which does not take the local common property into account and fosters the mere physical transplantation of objects could be described as spurious or window-dressing modernization, since it allows of the ephemeral reproduction of imported modernization, at a cost in foreign exchange that would be difficult to finance in the coming decade, but does little to spark off local innovation processes, without which participation in international markets becomes essentially precarious.

It is important to point out that in the foregoing description of the "endogenous nucleus of technological dynamization" no mention has been made of the size of markets or natural resource endowments. This is due to the conviction, corroborated by past experience, that there is no clear correlation connecting the dimensions of leadership and of economic and social linkage with size, much less with the endowment of natural resources. What has been said does not invalidate the importance of economies of scale and of concentration in specific activities, but seeks to underline how decisively important it is that the structure of productive activity, as a reflection of domestic creative effort, should be functional to specific national needs and potentialities. It is in this concrete sense that the term "endogenous" is applied.

The necessity of competing, reinforced by the limitations of domestic market size, and the learning process required, should inevitably be reflected in production profiles more specialized than those existing in advanced economies. The concept of "endogenous nucleus of technological 
dynamization" is favourable to the identification of lines of specialization and the creation, on the . basis of these, of more and more closely-knit systems which strive to reach levels of international excellence in the various links that make up the specialization chains. The particular development pattern of the industrial sector in the Latin American region is obviously at variance with this criterion of selection and specialization.

\section{III}

\section{The false dilemma: import substitution strategies or export-oriented strategies}

The assertion that Latin America would seem to have witnessed the failure of "importsubstitution strategies" and that it is expedient to enter upon the phase of "export-oriented strategies" is a simplification of the debate and of the economic reality, in connection with whose normative repercussions some reservations should be formulated. ${ }^{1}$

The merits of industrial exports are indisputable: they promote economies of scale and growth; they strengthen the capacity of adaptation, through the technological learning process, inter alia, to the changing conditions of the international economy; they help to improve the terms of trade; and, in a period marked by shortage of foreign exchange as a constraint on growth, they obviously acquire even more importance. What is less obvious is the mode of procedure whereby, starting from a situation characterized by the dearths and the assets accumulated in Latin America's previous industrialization phase, the requirements can be met that empirically and theoretically condition the possibilities of international competition.

For this construct, which sets "importsubstitution strategies" and "export-oriented strategies" against each other, as if they were mutually exclusive options, to be substantiated

\footnotetext{
${ }^{1}$ It is not only in Latin America that the criterion of simplicity is applied in seeking economic options; the same thing happens in the ad va nee $\mathbf{J}$ countries, where Manchesterian utopias compete with those that are turning Japan into a paradigm, and this reflects the perplexity and the existential need behind the search alluring formulas which would make it possible to surmount, not only the crisis in the real economy, but also the crisis of theoretical thinking.
}

with a minimum of rigour, it would be necessary to show in the first place that import substitution has been a specific feature of industrialization in Latin America and that, in that sense, the region would seem to have diverged from the traditional industrialization route followed by the economies which are mature today or by other late-industrialization economies. Secondly, it would be necessary to prove that this potential specific feature has been the most important of the factors accounting for the unsatisfactory results achieved in such spheres as employment, income distribution, external vulnerability and the absence of autonomous technological innovations (a determinant of the possibilities of competing on the international market). Thirdly, it would be necessary to demonstrate that those successful instances of late industrialization, particularly in South-East Asia, which are the tacit or explicit frame of reference for the recommendation in vogue today, are essentially attributable to an export vocation, and to relegate other economic, social, political and cultural factors which formed the context in which that industrialization was introduced - and in respect of which there are striking differences from Latin America's experience - to a marginal role in the explanation of the results obtained. Lastly, consideration would have to be given to the feasibility of a possible mass outflow of exports from the semi-industrialized countries in face of an international market which looks likely to be 
less dynamic than in the past. Attention is concentrated, however, on the factors mentioned above, inasmuch as internal requirements are deemed to play a bigger part than international demand conditions in determining the notable national differences in the capacity to export manufactures. To assume that the international market could have room for a large number of "Koreas" is an obvious fallacy, but that is not an argument which refutes, in relation to national cases, the generic thesis positing that import substitution should be shelved and that the economy should become export-oriented, i.e., the question which is at issue here. The experience of the past, real cases of recent date, and the theoretical baggage available, suggest that simple and precise answers to the foregoing problems could hardly be found. Accordingly, this proposition needs toning down, and to that end it must inevitably be postulated that the complexity of development strategies is such that simplified versions, which contrast the "virtues" of exports (frequently in association with the pre-eminence of market principles) with the "nefarious" connotation of import substitution (which would seem to reflect excessive intervention by the public sector) are an inadequate framework for thinking about strategy in the conditions currently prevailing in the regional and international economy.

Attention will next be devoted to certain aspects of the problem which are sometimes omitted or confused, with the result that the normative repercussions of the debate are distorted. In the first place, it should be pointed out that a basic feature of "export-oriented strategies" is their markedly industrial character, which finds expression both in the high growth rates of manufacturing output and in the speed with which changes take place in the structure of production under the leadership of the industrial sector. In countries like Japan, Korea and Taiwan average annual industrial growth rates in the 1950s and 1960s attained approximately $15 \%$, i.e., doubled that of the countries with the greatest industrial dynamism in our region (Brazil and Mexico). This explains the fact that the degree of industrialization of the Asian countries (measured by the share of the industrial product in the total product), which at the beginning of the 1950s was lower than or comparable to that of the most industrialized Latin American countries, was significantly higher at the dawn of the 1970s and that, owing to the industrial setback experienced by Latin America in the early 1980s, this difference had been considerably accentuated by 1983 , when the degree of industrialization in Japan, Korea and Taiwan exceeded $40 \%$, whereas it reached $25 \%$ in the larger Latin American countries and 23\% in the region as a whole.

The rapid growth of the industrial sector in the countries with an export vocation, linked to the internal learning process, set in motion the "vicious circle" of industrial growth, upswing in productivity and technical progress, and increasing participation in the world market for manufactures. It must be stressed that the part played in international markets cannot be understood unless account is taken of background material such as the industrial dynamism and technical progress of the structure of production in the countries concerned.

This last question is directly connected with another that has sometimes been the object of simplifications bordering on confusion. The terms "import substitution" and "home-market orientation" are often used indiscriminately, which gives the impression that the dynamizing effect of expansion of the domestic market is conditional upon the intensification of import substitution, whence the inference is that if the possibilities of carrying import substitution farther seem to be limited, the international market becomes the only dynamizing option. The indiscriminate use of the terms "import substitution" and "domestic market" may be conducive to ambiguities. It may happen that the dynamizing effect of expansion of domestic demand is accompanied by an intensification of import substitution (decrease in the import coefficient), by a reduction of import substitution (increase in the import coefficient) or by a neutral import substitution process (constant coefficient). In the first case, the dynamizing effect on domestic production produced by the expansion of final domestic demand is reinforced by the incidence of import substitution; in the second, from che contribution made by the increase in domestic 
demand must be subtracted the effect of the more than proportional increase in the import component; in the third, influence is exerted only by the growth of the domestic market, unadjusted by any import component effect. Consequently, import substitution is of help, particularly during the initial phases of the industrialization process, in dynamizing local production, but the latter can expand in the absence of import substitution and even in the presence of its reduction.

Some empirical examples may be of assistance in shedding light on this question in the case of Japan, which is the most notable example of dynamism and penetration into the international market for manufactures; throughout the whole industrialization process the increase in final domestic demand accounted for at least $70 \%$ of the production increment and, in some recent periods, for more than $80 \%$ (Kubo and Robinson, 1984). Between 1915 and 1955, the contribution of import substitution to the growth of production was positive and as from that date negative, although marginal. That of exports, positive before 1935 and after 1955, fluctuated between $10 \%$ and $20 \%$ of the increase in local production.

In the case of Korea and that of Taiwan, up to 1970 the dynamizing effect of the growth of the domestic market did more than export expansion to step up production. In Korea, the import substitution effect was equivalent in the period 1955-1963 to four times the contribution of export expansion to the growth of local production, and subsequently became negative, although marginal. In the case of Taiwan, the incidence of import substitution was comparable in the period 1955-1961 to that of export expansion, and both fell short of the contribution made by the increase in domestic demand. In the following period, 1961-1966, the home market stayed in the lead, but the import substitution effect was reduced, although it was still positive; in the period 1966-1971, during which the most important dynamizing factor was export expansion, followed by the enlargement of the domestic market, import substitution continued to make a positive, although marginal, contribution.

The upswing in domestic demand was responsible for over $80 \%$ of the increase in local production in Mexico as from I960, while over the period 1950-1970 import substitution accounted for approximately $10 \%$ of the production increment, a proportion slightly more than double the contribution of industrial exports; from 1970 onwards, the contribution made by the expansion of industrial exports exceeded that of import substitution ( $8 \%$ and $3 \%$, respectively). Colombia, the other country of the region for which comparable estimates have been made, shows a similar profile.

The foregoing data, besides bearing witness to the importance of use of the terms "import substitution" and "domestic market" and highlighting their different contribution to the dynamism of production, suggest the existence of a time linkage between "import substitution" and "outward-directed development" incompatible with those simplifications that present them as mutually exclusive options. To this third aspect of the question attention has been repeatedly drawn by BCAC in earlier studies. But behind the successes referred to (export-oriented strategies) there lay a period of extensive import substitution and technological improvements during which domestic industries developed and strengthened their capacity for international competition. Without this preparatory stage, perhaps industrialization could not have been successfully consummated through export expansion in the economies concerned (Kubo and Robinson, p. 245. See also BCAC (1959 and 1977)).

The recent increase in Brazil's industrial exports would be incomprehensible without the effort previously expended on constructing an industrial base, notwithstanding the inadequacies of the industrial pattern, a subject to which reference will be made later.

It should be pointed out that even in the periods when the export of manufactures has been the main factor accounting for the increase in local industrial production, import substitution has coexisted with export expansion. At the world level mention has already been made of the cases of Japan and Korea, Taiwan, Mexico and Colombia, and, at a disaggregated level, it is interesting to single out the situation of Korea, where, in 1965-1970, approximately $60 \%$ of the increase in exports derived from sectors in which import 
substitution made a positive and simultaneous contribution to the rise in industrial output. In the period 1970-1975 the proportion in question was reduced to $30 \%$ (Tori and Fukasau, 1984).

Another aspect worth taking into account is the level of aggregation at which the analysis is carried out, both for methodological reasons and because of the types of conclusion to which it may give rise. Since import substitution is measured, for analytical purposes, by the variation in the corresponding import coefficients, it may happen that an import substitution process appears with a positive sign at one level of aggregation of the analysis and with a negative sign at another, the explanation of which lies in the variations occurring in the structure of domestic demand. Thus, for example, it may also happen that measurement by branch of industry suggests an intensification of the import substitution process (the import coefficient has decreased), whereas for the economy as a whole import substitution has undergone a setback. For this, it would be enough for those branches with a high, although declining import coefficient to show a growth rate considerably outstripping that of branches with a lower import coefficient, a phenomenon, moreover, which is common in Latin America.

But what matters more than this optic effect associated with the level of aggregation is to stress the enormous importance that for the purposes of policy interpretation and design attaches to analysis of the modifications undergone by the structure of production, whence it necessarily follows that at least as much significance must be conceded to the sectoral as to the global level of analysis of import substitution and of export promotion. Economic development implies changes in the structure of demand and of production, accompanied by technical progress. Consequently, analysis of import substitution and of export promotion, partial constituents of the development process, must incorporate this transformation of the production system as one of its elements if the dynamics of development is to be more thoroughly understood. It is evident at a glance, for example, that in post-war growth the changes in the structure of production were characterized by the greater dynamism of intermediate inputs in common use - steel and petrochemical products-, of the capital and durable consumer goods included in the nonelectrical and electrical machinery branches, and of the transport equipment sector. Once this basic feature of the industrialization process in recent decades has been recognized, analyses and recommendations in respect of import substitution and export promotion will prove inadequate if they fail to incorporate the evolution through time of the changes introduced and the policies adopted in these branches which are of strategic importance both from the standpoint of transformation of output and from that of dynamism in the international market and of trends in the incorporation of technical progress.

To illustrate the combined effect of the various aspects mentioned, it is of interest to revert to the case of Korea. If the period 19551973 is considered as a whole, export expansion figures as the engine, of growth of local production, accompanied in the second place by the expansion of domestic demand and followed by a marginal but positive contribution from import substitution. If the analysis is broken down by three subperiods, a closer approximation to reality is obtained, but with different indications for interpretation purposes: in the period 1955-1963 the growth of the domestic market, strengthened by import substitution, accounted for almost $90 \%$ of the increase in industrial production; in 1963-1970 the domestic market was still a spur to growth, now followed by export expansion, and import substitution appears as negative. Only in the final subperiod, 1970-1973, which witnessed the culmination of the foregoing process, did export expansion become the engine of growth, followed by the enlargement of the domestic market and a negative import substitution effect for the economy as a whole. If to this breakdown by periods of time the sectoral dimension is added, new indications are obtained which are of importance for the interpretation of this industrialization,process. Although in the period 1966-1970 import substitution was negative for the economy as a whole, in 14 out of the 25 branches of production the import substitution process was pursued in greater depth. Yet more important, however, is the fact that the main import substitution effort was concentrated in 
branches which are strategical from the three points of view mentioned above: petrochemicals, iron and steel and the production of transport equipment. In the two last-named, import substitution did more than exports to boost industrial production. In the next period (1970-1975), the import substitution effort continued less vigorously in the petrochemical and iron and steel branches and was accentuated in non-metallic minerals and metal products, a major import substitution effort being launched in capital goods. In the case of non-electrical machinery, which properly speaking is a capital good, the contribution of import substitution was similar to that of export expansion, and together they were equivalent to approximately $80 \%$ of the contribution to the growth of industrial production made by the increase in domestic demand.

If the images obtained from the aggregate analysis, without differentiation of the periods in which industrial policies undergo modification, are contrasted with the indications deriving from the analysis broken down by periods of time and sectors, it is obvious how far simplifications in analysis may introduce distortions into recommendations. The situation becomes even more serious if the case in question constitutes the basic argument for the construction of a paradigm susceptible of universal application.

From all that has been said above it can be inferred that the use of import substitution as an instrument of industrialization is neither peculiar nor specific to Latin America. Rather was it the basic expedient used by the economies which are mature today in building up their industrialization process (with the obvious exception of the United Kingdom at the end of the eighteenth century and the beginning of the nineteenth, since it had nowhere to import manufactures from) and the same is true of a late-industrialization economy participating more dynamically in the interntional market, like that of Japan. Even in the case of some countries of Southeast Asia, such as Korea, the combined use of selective import substitution and export promotion is a fait accompli in practice today. What is specific to Latin America is the particular modality, marked by the absence of creation, adopted in the import substitution process. The following are among the features wherein Latin America's industrialization specifically displays striking differences from that of the countries with mature industrialization and the late-industrialization countries of Southeast Asia: the high and indiscriminate level of protection afforded, which, in conjunction with exchange policies, has fomented higher rates of return in the domestic than in the international market, with notable and permanent differences; the types of sector to which protection has been given; the agents that have been bearers of industrial growth; the atomization of the structure of production; the acritical reproduction of a consumption pattern which has not been functional to the needs of the region and its existing potentialities; the asymmetry between industrial and agricultural development, which has made for the persistence and, in some countries, the accentuation of structural heterogeneity, especially with regard to the production of basic foodstuffs for domestic consumption; the dysfunctional energy base utilized; the relative lag in the capital goods sector; the partial distortion of financial intermediation in the direction of short-term financing; and the insufficient weight carried by the domestic entrepreneur in the more dynamic industrial sectors.

This list, however incomplete and schematic, suggests that any appraisal of the results of Latin American industrialization must take into account a wide range of economic, social, political and cultural factors, which together would explain the gestation of this very special mode of growth. Apparently, the basic feature of industrialization in the mature economies of today, and also in those of Southeast Asia which carried out the process more belatedly, can be said to He less in the use of specific policy instruments - which, in general, are reproduced in Latin America, although with different weightings - than in the closely-knit character of these societies, the result of historical processes which in the political sphere are typified by a clear leadership, accepted and recognized by the rest of society. Although this leadership, whose origin and nature vary according to political systems and different periods, as do also the social sectors and 
institutional modalities by which and through which it was exercised, was not exempt institutionally from conflicts and even breakdowns, it was favourable to the definition and relative stability of long-term strategic options.

These options, combined with the existence, at the social level, of minimum norms of solidarity - which for the sectors exercising leadership implied the assumption of certain responsibilities towards the subordinate social sectors, associated with a sense of belonging to the national entity - helped to spread belief in the prospect that the inequitable initial situation would gradually be set to rights. The projection of this evolution in the economic sphere took the form of a linkage between State and society, with modalities that obviously varied with systems, histories and periods and that fostered the acceptance of an order in the framework of which a gradual process of cultural integration and technological learning was generated. Thus each country's national objective of strengthening its relative importance in the international economic concert was made viable.

In the determination of the international competitive potential of the aforesaid development processes in closely-knit societies with leadership, gradual construction of a consensus, minimum norms of solidarity and linkage between State and society, a basic feature was precisely the existence of the "endogenous nucleus of technological dynamization" defined above, which ensured the continuity of a process of assimilation, learning, adaptation and innovation functional to meeting internal needs and turning local potentialities to advantage. This "endogenous nucleus of technological dynamization" guided import substitution and accounted for its simultaneous progress alongside gradual generation of exports on the basis of a systematic learning process.

In countries endowed with an abundance of certain natural resources, even though the domestic markets were small, the learning process implied an intellectual value added which made it possible to reach levels of excellence in the sphere of manufacturing techniques and of the equipment required to exploit and process the natural resources in question, as well as to find new uses for them and new designs associated with their utilization. This is the situation, for example, in the Scandinavian countries, which carry considerable weight in international trade in manufactures, technologically linked to the endowment of natural resources. The comparative advantage built up with the help of domestic creativeness, making the most of natural resources in small markets, is the practical expression of the existence in those countries of the element which has been defined as an "endogenous nucleus of technological dynamization", and which serves as a mainspring of viability for the national objective of survival and ever-increasing relative importance in the international context; the same thing is observable in countries that are lacking in natural resources.

Cases in point are afforded by countries like Japan and its former colony, Korea, in which it was precisely the relative shortage of natural resources that constituted the main mobilizing factor in the process of innovation required to make up for that insufficiency through the capacity to compete internationally in the processing and manufacturing phase. It was a matter of facing the challenge to survive and defend their existence as national entities; in those countries, the process of modernizing agriculture, with differences in pace and intensity, preceded and then accompanied the industrialization process, just as in the Scandinavian countries and in those that gave impulse to the first and the second industrial revolution, the United Kingdom and the United States. But in this second group of countries, which followed the path of modernization from below, the relative participation of the market with respect to the State was greater than in the first group. In the case of Japan, whose industrialization was late, and in that of Korea, where it was still more belated, the State fulfilled a decisive function in the linkage and modernization of the activity of the various agents and sectors from above, which proved functional for this transcendent national aim of survival and betterment of the population's level of living, strengthened, in both instances, by obvious geopolitical motivations. The initial export of light manufactures involved, like protection, a learning process which was to 
make it possible gradually to evolve towards technology- and capital-intensive manufactures, but the decisive factor in that evolution was the association, learning, adaptation and subsequently innovation effort, of fundamental importance for competing in the international market, in turn a determinant of national survival.

The participation of these countries in international markets is largely explained by the higher priority they conceded to the learning process and to the building-up of a technological infrastructure, as well as to the latter's linkage with the production sector, and by a systematic policy of support for small and medium-sized firms organically linked with leading enterprises. One of the basic requisites in all these experiences was the way in which the private interests of the social sectors that exercised leadership were subordinated to the national interest, making it easier for the rest of the society to take the view that although to begin with the wages and income distribution situation was inequitable in comparison with that of Latin America, there was room for hope that under this conduct, not exempt from coercion but bold, austere and self-identified with the national interest, the subsequent evolution of the economy and of society would gradually tend to even matters out.

\section{Industrialization strategies and the curious State or market dilemma}

Financial intermediation, which has indubitably followed different institutional patterns in Western Germany, Japan and Korea, nevertheless has in common in those cases the fact of having been systematically at the service of a resolute policy of industrialization and innovation aimed at upgrading the possibilities of international competition. This common feature seems to be of greater importance than differences with regard to the public or private character of the financial sector or to the practical pattern of linkage between it and the industrial sector; in one case industrial development was conducted by a financial sector committed to industrialization and the long term; in others that sector functioned as a support service for the leadership exercised by the industrial groups themselves. In the case of Korea, up to the beginning of the 1980s, it performed an almost exclusively public supporting function of preferential channelling of subsidized resources towards the strategic objective of promoting the growth and technological learning process of the private national groups which gave impulse to the country's industrialization. As an example worth quoting of the pre-eminence of investment over consumption, up to 1981 colour television sets that the country manufactured and exported were not sold on the domestic market to prevent a decline in family rates of saving.

What has been said of the linkage between financial intermediation, the State and the industrialization process constitutes a special illustration of the reservations that should be borne in mind with respect to precise recommendations on the paradigmatic function of the market. Its function has in fact been important in those historical experiences in which modernization from below generated forms of social organization characterized by relative symmetry in access to economic and political power and culminating in democratic institutions compatible with the political alternation which is based on the existence of a high degree of consensus respecting the merits of the existing system. In cases of late industrialization, the weight carried by the 
State in the development process has been decisive and much has been written on the subject. It is interesting to stress that in those instances -among which appear some European countries and Japan- where democratic institutions were introduced after the Second World War, political alternation is not yet an established practice.

When attempts are made, in societies that are characterized by asymmetry in access to knowledge, to information and to economic and political power, to impose it from above, or on the basis of doctrinaire considerations assigning the central role to the market and a subsidiary function to the State, dynamics of concentration and speculation are generated. These have destabilizing consequences which, paradoxically, induce the State to intervene and to expand its role, and even to overstep the limits by which that role was bounded in the preceding phase.

In the light of these considerations, the linkages between State, market and industrialization strategies are patently subjects in connection with which it is hardly possible to formulate narrow recommendations in which no heed is paid to national sociopolitical specificities. The diversity of situations within Latin America is so obvious that, given the level of abstraction and generality at which the present article is written, all that can be offered is a very modest methodological suggestion, prompted by recent events: namely, that as regards encouraging the insertion of national firms in international markets and making it technologically and financially viable, a decisive function of guidance and catalysis is incumbent on the State. With specific reference to the technological sphere, it might be asserted that in view of the peculiar qualities of technology, which is at once merchandise and service, and of the acknowledged distortions that characterize the international market in which it is traded, it is the function of the State to guide and link up the innumerable private agents that participate in the technological development process on which competition at the international level is based. On the financial side, the contribution made by the governments of the OECD countries to the adjustment process in their industrialtechnological systems is an unmistakable pointer which Latin America cannot afford to ignore. $^{2}$

It is obvious at a glance that the capacity to generate industrial exports clearly reflects the quality of industrial development, and that an industrialization process which is capable of gaining and keeping a foothold in the international market with its manufactured products is better than one which does not succeed in doing so. It is not to be inferred, however, from this virtually redundant assertion, that the problem can be resolved by assigning to export promotion a quasi-magical function in supplying the inherited wants that have been accentuated in the recent period of crisis. Even if the criterion were adopted that industrial exports measure, in a sense, the success of industrialization, the real problem posed (theoretical and practical) consists in identifying the combination of measures, instruments, policies and institutions, at the macroeconomic, sectoral, regional and even microeconomic levels, which can gradually shape production systems and institutional frameworks with learning and innovating capcity, a highly relevant issue in this transitional phase of industrial-technological patterns at the international level. Neither chance nor greater or lesser knowledge on the part of the respective economists can account for the very small number of cases of late industrialization that are export-oriented.

The non-existence of an "endogenous nucleus of technological dynamization" in some countries of the region and its precariousness even in the countries of larger size and a more advanced degree of industrialization explain why the designing of products, processes and manufacturing techniques has not been functional to the satisfaction of domestic needs and the exploitation of local potentialities. It likewise accounts for the existence of structures of production that are fragmented in relation to

\footnotetext{
${ }^{\mathrm{J}} \mathrm{A}$ suggestive and vigorous analysis, from a neoclassical standpoint, of the function of the State and the limitations of the market in the industrial and technological development of semiindustrialized countries appears in Howard and Westphal (1985). For the most recent quantitative data on the public contribution to the financing of research and development activities in the OIICD countries, see Ol-CD ( 1984)
} 
the size of the domestic markets, the failure to take sufficient advantage of the agricultural, forest, fishing and mining resources available and the inadequate energy base which has supported the industrialization process. This and other factors, which in the last analysis are linked with the process of gestation of the Latin American societies and with their evolution in recent decades, suggest that with a few exceptions in individual countries and particular periods, the industrialization process has been inserted in a setting characterized by precarious ness of internal consensus and leadership, by predominance of private interests over the national interest, by a generally high degree of social fragmentation and economic exclusion which accounts for the frivolous nature of import substitution, and by the relative insignificance of industrial exports (the industrial exports/industrial output and industrial exports/total exports ratios are notably lower even in the more advanced countries of the region, like Brazil, than in other countries and regions with a comparable degree of industrialization).

In short, when there is no "endogenous nucleus of technological dynamization" or when it is insufficiently consolidated, an industrialization process is generated in which the foreign exchange balance is much more unfavourable than it might be in conditions in which the size, market and resource endowment of the various protagonists were the same, but in which the value and incidence of entrepreneurial function, whether public or private, were definitely appreciated. This more unfavourable foreign exchange balance stems from the relative incapacity of local production to compete internationally against potential imports from foreign markets, an incapacity which, in consequence of insufficient internal creative effort, is reflected in and reinforces unnecessary use of foreign exchange. In practice, this means the consolidation of a structure of production which uses imports that are unnecessary under the head of design and information, a statement applicable both to the design of energy, transport, health, communications, housing, education and food supply systems, and to that of industrial products functional to local conditions; the deficiencies at this level make themselves very keenly felt in the following respects: i) inputs, since local raw materials, foodstuffs and energy resources are not exploited; ii) manufacturing techniques, as regards both the inappropriate use of manpower and the failure to take advantage of traditional organizational patterns which could be modernized without losing their value; and iii) capital goods, both through the importing of goods that could be locally produced, and through the waste of capital goods immobilized in an atomized structure of production with a high degree of idle capacity, besides overspending on armaments.

Insufficient industrial exports and unnecessary imports are head and tail of the same coin: the absence of creative activity. They join forces and converge to account for the external bottleneck. It is idle to cherish the illusion that a high exchange rate, together with institutions specializing in export promotion and a marked contraction of domestic demand, will be enough in themselves to supply the deficiencies mentioned, although obviously they help to discourage imports - not necessarily those that are non-essential- and to stimulate the promotion of exports which do not require domestic technological effort and the release of surpluses by virtue of the decline in domestic consumption. Rationalization of the existing structure of production, correction of the industry-agriculture asymmetry, selective channelling of financial resources into the sectors that give impulse to industrialization (which obviously vary according to the countries concerned), and linkage of the educational system, the mass communication media and the scientific-technological infrastructure with the productive system, are some of the basic requisites for setting in motion an internal innovating process capable of contributing to the sound and sustained enhancement of the capacity for international competition, on the part both of import-substituting products and of those intended for export.

The advanced and late-industrialization countries which have successfully made their way into the international markets have clearly understood that concerted and sustained national action, with long-term projections on the technological level, is a sine qua non for 
building up future comparative advantages. It is worth while to quote recent and irrefutable examples, totally different in nature, in which action of this kind has been taken (in addition to the current national technological policies of the advanced countries, mentioned above): Korea's ongoing policy (Chon, 1984) in the electronics sector and, in the United States, the policies of the various states (Brody, 1985) which compete for the location of high-technology enterprises in their territories. These instances reveal a long-term outlook, the participation of the public sector at the level of definition of priorities, the channelling of financial resources on preferential terms, and the existence of fiscal incentives, of a scientific and technological infrastructure and of human resource training activities, and all this in close linkage with the large, medium-sized and small national firms which are giving impetus to industrial development today or might do so in the future. Some countries in the region are beginning to awake to the necessity, in face of the economic crisis and external constraints, of introducing innovations into the industrialization pattern in a direction compatible with what has been said here: this new awareness is exemplified in the rationalization of the motor-vehicle sector, which acted as a stimulus in the preceding phase of industrialization and whose central objective is to improve the foreign exchange balance; the initiation of rationalization programmes in energy consumption, a sphere in which the region, with the exception of Brazil, has displayed great inertia; support for local production of basic foods for domestic consumption, a matter which must be taken into account both in relation to external constraints and in connection with its contribution to the viability of democratization processes; the establishment of systems of concertation between the public sector and entrepreneurial activity, particularly in the sphere of export promotion; a lowering of protection in countries where a certain inertia in this respect predominated and an increase in it in those cases where a radical and indiscriminate reduction had taken place; and, lastly, a generalized conviction that linkage between the scientific and technological systems and productive activity is vital for surmounting external constraints. These measures and convictions are auspicious signs, although fragmentary, partial and insufficient, of incipient internalization of the idea that action must be taken on a number of fronts all at once, in order to evolve in the direction of a new industrialization pattern, functional to the task of meeting needs on the basis of systematic development of domestic potentialities, compatible, at the same time, with the requirements of the international market. To this end, it must be recognized that the complexity of the challenge transcends both the proposition that eliminates the inefficiencies of industrialization by questioning their existence, and that which pins the hope of overcoming them to the perpetuation of the previous industrial pattern for as many decades as it might require to make up its leeway from biological causes. The first of these options has given empirical proof of its results, and the second is totally non-viable, even if only on account of the familiar external constraints.

Education, and the use it has made of the mass communication media, on the basis of the most modern techniques available, may exert an influence on the attitude of the various social agents that participate in the economic process, exceeding in importance each of the individual instruments of commercial policy. This subject, which is analysed in the section on technology development, illustrates the need to tone down the simple and therefore attractive options which make individual instruments of trade policy the centre of attention. The view held by society as a whole of the national vocation of those who exercise leadership, the social valuation of innovation and of the entrepreneurial function in a broad sense of the term, are factors determining the possibility that the economically difficult conditions in which most of the Latin American population will live during the coming decades may be accepted as a legitimate period of transition leading to a more favourable future prospect. Whatever may have been the initial income distribution conditions in the various Latin American countries, the decisive factor is the achievement of modes of social concertation which will legitimate leaderships, so that in this period of economic hardships it may be possible to prevent fragmentation from being accentuated and, in some cases, the very survival of national States from being called in question. 


\section{On the supposed emergent leadership of the services sector}

\section{Twilight of industry or complementarity}

Wide currency has been gained by the idea that a transition is taking place from an era in which the driving force has been the industrial sector to a future in which this role will correspond to services, the agriculture-industry-services sequence being thereby completed. This notion is based on two simple and for that very reason beguiling observations: the rise in income generates a more than proportional demand for services; and as the expansion of employment in services thus exceeds that of total employment, a growing proportion of jobs is to be found in the services sector.

On the basis of this idea policy recommendations have been formulated in Latin American countries which have favoured the dismantling of industrial plant in order to hasten the advent of the new era. In this connection, however, several comments are called for which, taken as a whole, alter the linear image of an agriculture-industry-services time sequence, and some of which are briefly outlined below. In a high proportion of services the reason for their expansion líes $i n$ the changes undergone by the manufacturing sector as a result of income increases, keener international competition, and the growth of the public sector. The services generated by these changes maintain close technical linkage with the industrial sector, with which they build up relations of complementarity, not, as might be deduced from the original thesis, of substitution.

The following are some of the changes in the industrial sector which give rise to the expansion of specific services:

i) The increase in consumption of durable goods, motor-vehicles and electrical household appliances, leads to the expansion of financing, marketing, maintenance and publicity services, and the jobs generated in these activities quickly outnumber those required in the production phase; ii) The decline of the rate of return in the industrial sector, which began at the end of the 1960s, accounts for the channelling of resources towards those services associated with the socalled "paper entrepreneurialism", with the consequent growth of the commercial, financial, legal advice and real estate intermediation sectors. A recovery in the rate of return would tend to modify the proportions observed during the crisis period;

iii) The shift of focus of competition from prices to differentiation of products is a stimulus to publicity and marketing services;

iv) Technical progress in the industrial sector cuts short the working day, which demands increasingly less physical effort, both at the place of work and in household activity. Consequently, there is an increase in demand for entertainment services, which incorporate, furthermore, consumption of industrial goods and equipment (television sets, sports equipment, tourist facilities, etc.). ${ }^{5}$ The leadership of the United States in the entertainments "industry" is a factor of vital importance in evaluating its future insertion in the international economy;

v) The stepping-up of competition at the national and international levels encourages specialization in activities producing goods and in those services that were formerly incorporated in firms, and that are becoming independent entrepreneurial activities: computer services, engineering firms, management of financial activities, etc.;

vi) The internationalization of industrial activity fosters the internationlization of the services activities connected with it, which explains why it is just those countries whose services activity abroad is greatest that are the

'It is estimated that at the beginning of the century the annual number of working hours per man was 140000 , and that today it has probably been reduced to 72000 hours per year (Tsuru, 1983). 
most enthusiastic promoters of the liberalization of international trade in services;

vii) The systematic expansion of the public sector in industrialized economies, resulting from a complex process in which legitimization and accumulation requirements proper to industrialization and to urbanization are combined, generates, on the one hand, the expansion of specific public services such as education and public health; on the other hand, through increasing regulation, it leads to an entrepreneurial reaction which is reflected in a wide variety of advisory services supporting firms in their linkage with the State.

Hence the inference is that there is no magical relationship between rising income and demand for services; in contrast, an economic and social transformation is taking place which simultaneously modifies the industrial sector and a variety of services that are linked with it in relationships which differ in kind, but nevertheless point towards complementarity (Stanbaek, et alii, 1983, p. 40).

\section{Incidence on employment}

A major share of the increase in employment $i n$ the services sector is located in activities whose level of productivity is low and static; retail trade, health and education. In these activities, price levels have shot up much faster than in industrial activities. Thus they have become a source of inflationary pressure that is by no means negligible and a factor which partly accounts for the decline in the growth rate of global productivity.

In the case of the health sector, mentioned as one of the most outstanding examples of the relation between rising incomes and demand for services, the growth rate of prices has been so high (especially in the United States, but also in other industrialized countries) that there is a growing awareness of the imperative need to introduce institutional and regulatory changes which will make it possible to raise productivity and contain price increases.

Generally speaking, services activities where productivity is low and stationary can be said to be representative of the initial phase of an industrialization process, i.e., the introduction of industrial logic, with the consequent presence of production equipment and processes deriving from industry. This can be clearly seen in marketing, health and training services, and even in such tertiary activities as hairdressing establishments and psychiatric clinics (Druker, 1984).

In so far as the industrialization of lowproductivity services continues, with an everlarger contribution from information sciences, these activities will tend to do less and less to expand employment. Services in which productivity is high and increasing, such as communications, financial services or wholesale trade, are characterized by their high degree of industrialization, with much less and more slowly-growing employment than is found in low-productivity services.

\section{Leadership of communications}

From the standpoint of supply, the basic factor accounting for the so-called revolution in information sciences is the rapid technological progress recorded during the 1970s in the microelectronics, telecommunications and computer spheres; this explains the steep fall in costs of transmission, processing, storage and reproduction of information. In other words, it is the technical progress generated in a few branches of the industrial sector that makes it possible to sustain the simple and alluring slogan that in the future information sciences will take the place of capital and labour as basic factors of production. It is not by chance that the communications sector, the most industrialized of services, is the one that seems to be assuming the leadership in the transformation that is being undergone by the structure of production of goods and services as a whole. Indeed, as regards the attributes of leadership — growth rates of output, of employment, and of productivity, the level of productivity and the rate of decline of relative prices - the only sector of production that shows more favourable levels than the economy as a whole in all those five indicators at once is the communications sector.

In the manufacturing sector, this privileged situation of the communications sector is shared by activities in which hardware is strengthened (the physical component of the so-called information technologies, microelectronics, 
computer sciences and telecommunications). If an attempt were made to identify the sector that stands out as having most drive, it would be located at the point where linkage occurs between those industrial sectors that produce information technology equipment and the service activities that transmit, process and disseminate information. Starting with these sectors, ongoing technical change spreads, at different rates and in different forms, to the whole set of activities producing goods and services. It is a question of leadership of what might be termed the information sciences system, which comprises a symbiotic combination of hardware and software.

\section{Insertion in the international economy and industrial competitiveness}

The countries' possibilities of international competition and their prospects of long-term insertion in the world economy are still essentially determined by the efficiency of their respective industrial sectors, generators of the technical progress which spreads to other activities and influences their levels of productivity. In a period of recession, a country may cope with the problem of unemployment by expanding services not exposed to international competition, an option in which Latin America has plenty of experience; nevertheless, over the medium and long term the question of international insertion ís still determined by the competitive capacity of industry and of the industrialized services linked to it.

Hence can be inferred the importance of incorporating into medium- and long-term analysis of the new industrialization the changes under way within the industrial sector, the increasing complementarity between the industrial and services sectors, the trend towards industrialization of activities previously classified as tertiary, the emergence of a leadership of the information sciences system with its hardware and software components articulated around the axis of communications, and the consequent importance of the competitiveness of the manufacturing sector in determining the degree and form of Latin America's insertion in the international economy.

\section{Concluding remarks}

From all that has been said it may be deduced that in analysing the present financial crisis of the Latin American countries it is indispensable to take into consideration, in addition to the above-mentioned external factors, the structural aspects of the strategy pursued hitherto. The fragility of the external situation is closely bound up with this industrial pattern; the precarious leadership exercised by the motor-vehicle industry, combined with the dearth of capital goods and the lag in their production, the asymmetrical relationship between industry and agriculture, the dysfunctionality of the energy base, are the fundamental reasons for vulnerability to external causes and, consequently, for external indebtedness. An indispensable requisite for overcoming this vulnerability is the transformation of the industrial pattern in question, as well as of its linkages with the agricultural sector and environmental resources, with the energy base, with the financial intermediation mechanisms by which it has been supported, and with the various components of the services sector, especially the social services (health, education, housing) and communications.

In general, instead of a faithful but technologically dephased image of the 
industrialization of the advanced countries, what is to be found is a stunted and distorted reproduction of that original, model, which in part at least is ill-fitted to meet the needs of a large proportion of the population and which at the same time is incapable of developing its creative potentialities and taking full advantage of the abundant natural resources available. It would seem obvious that the neoliberal proposition, which deals with the inadequacies of industrialization by questioning their existence and backtracking to outdated schemes of an international division of labour under which the Latin American countries would figure as resigned to the dull and relatively insignificant function of exporters of natural resources, does nothing to solve the problem of accumulated social needs.
The assignment of strategical priority to the development of industrial exports, and to the rationalization of the inherited structure of production as a prerequisite for the viability of the foregoing objective - points on which there is a consensus - must be carried to the utmost extreme, in full awareness of the fact that a task of national dimension is being undertaken, which far transcends the sphere of trade policy and even that of economics. It is a matter of embarking upon a new development style which will promote both inward-directed linkage and the enhancement of external competitiveness. International experience suggests that the question is not one of options at opposite poles, but one of requirements which reinforce each other.

\section{Bibliography}

Brody, H. (1985), "States vie for a slice of the pie", High technology, January.

Chon, K. (1984), State of the arts series on microelectronics: Republic of Korea, UNIDO/IS.490.

Druker, P. (1984), "Our entrepreneurial economy", Harvard Business Review, Boston, Harvard University, JanuaryFebruary.

ECLAC (Economic Commission for Latin America and the Caribbean) (1959), The Latin American Common Market, United Nations Publication, Sales No.: 59.11.0.4.

(1977), Desarrollo, industrialización y comercio exterior, Cuadernos de la CEPAL Series, No. 13, Santiago, Chile.

Howard, P. and L. Westphal (1985), Industrial strategy and technological change: theory versus reality (study presented at a Conference on New Directions in Development Theory, sponsored by the University of the United Nations and the Center for International Studies, Massachusetts Institute of Technology), Cambridge, Mass.

Katz.J. (1980), Domestic technology generation in LOO a review of research findings, Buenos Aires (prepared as part of the
Research Program on Scientific and Technological Development in Latin America, jointly sponsored by ECLAC IDB, the International Development Research Center and UNDP).

Kubo, Y. and S. Robinson (1984), "Sources of industrial growth and structural change: a comparative analysis of eight countries", Proceedings of the Seventh International Conference on input-Output Techniques, Vienna, UNIDO.

OLCD (Organization for Economic Co-operation and Development) (1984), The service economy: conservation of human resources. Series 20, New York, Columbia University Press.

Tori, Y. and K. Fukasau (1985), "Economic development and changes in linkage structure: an input-output analysis of the Republic of Korea and Japan", Proceedings of the Seventh International Conference on input-Output Techniques, Vienna, UNIDO.

Tsuru, S. (1983), "Marchés et technologies: nouvelles relations internationales". Económica, Paris, CEPII 